\title{
A Rare Presentation of Conjunctival Myxoma with Pain and Redness: Case Report and Literature Review
}

\author{
Yu-Po Chen $^{\mathrm{a}}$ Swei Hsiung Tsung ${ }^{\mathrm{b}}$ Tommy Yet-Min Lin ${ }^{c, d}$ \\ ${ }^{a}$ Northwestern University, Feinberg School of Medicine, Chicago, III., USA; \\ ${ }^{\mathrm{b}}$ Department of Pathology, St. Mary's Hospital, and ' Wu-Fu Eye Clinic, Lotung, \\ and ${ }^{\mathrm{d}}$ Department of Ophthalmology, Taipei Medical University, Taipei, Taiwan, \\ ROC
}

\section{Key Words}

Conjunctival neoplasms, pathology $\cdot$ Conjunctival neoplasms, surgery $\cdot$ Myxoma, pathology

\begin{abstract}
Background: Conjunctival myxoma is a type of rare, benign tumor of mesenchymal cells, with fewer than 30 reported cases in the English literature. It is mostly an isolated occurrence but can sometimes be associated with systemic diseases such as Carney complex or Zollinger-Ellison syndrome. It is necessary in clinical practice to differentiate it from other similar lesions, such as amelanotic nevus, lymphangioma, myxoid liposarcoma, spindle-cell lipoma, myxoid neurofibroma, and rhabdomyosarcoma.

Case Presentation: The usual presentation of conjunctival myxoma is a translucent, wellcircumscribed, and painless conjunctival mass, but in this report we discuss an unusual case of conjunctival myxoma in a 47-year-old Taiwanese woman who presented initially with pain and redness. This atypical presentation complicated the diagnosis and the management at first. Surgical excision of the mass was performed. The mass was found to be a conjunctival myxoma. The patient subsequently underwent extensive evaluation but was found not to have any systemic diseases with known association with conjunctival myxoma.

Conclusions: In summary, we present a case of conjunctival myxoma in a 47-year-old Taiwanese woman. The initial presentation with pain and redness was atypical for conjunctival myxoma. The lesion was successfully managed with complete excisional biopsy.
\end{abstract}

Tommy Yet-Min Lin, MD, DMSC, FACS
No. 108 Chung-Chen Rd.

Lotung, I-Lan 265, Taiwan (ROC)

Tel. +886 3954 2416, E-Mail wufu.eye@msa.hinet.net 


\section{Introduction}

Myxoma is a type of benign tumor derived from primitive mesenchymal cells. It is the most common primary tumor found in the heart [1]. Myxoma can also arise in other locations, including bone, skin, skeletal muscles, gastrointestinal system, and genitourinary systems. In the eye, myxomas have been found to involve the orbit, the cornea, and the conjunctiva [2,3]. Conjunctival myxoma is extremely rare, representing only one case among the 1,643 conjunctival lesions surveyed in a study $(<0.001 \%)$ [4]. We have found only 26 cases reported in the English literature. The typical presentation of conjunctival myxoma is a painless, circumscribed, rubbery, translucent/solid, yellow-pink mass or cyst [5-8]. Diseases that may resemble conjunctival myxoma include amelanotic nevus, lymphangioma, myxoid liposarcoma, spindle-cell lipoma, myxoid neurofibroma, and rhabdomyosarcoma [9]. In this report, we describe a case of conjunctival myxoma in a 47-year-old Taiwanese woman with an atypical initial presentation of pain and redness.

\section{Case Presentation}

A 47-year-old Taiwanese woman had a 3-year history of redness in her left eye prior to the initial visit. During these 3 years, she had been using unspecified kinds of ophthalmic drops sporadically. One month prior to the visit, she began to experience pain and irritation in her left eye and was diagnosed with allergic conjunctivitis and treated with cromolyn at another clinic. Her symptoms persisted for one month with no improvement from the treatment. Her past medical history was only significant for hypertension; she denied any ocular trauma in the past.

During the initial visit at our clinic, her visual acuity with correction was 1.0 in both eyes. A $6 \times$ $4 \mathrm{~mm}$ mass with surrounding hyperemia was noted in the left eye, situated on the bulbar conjunctiva and $0.5 \mathrm{~mm}$ temporal to the limbus at 3 o'clock (fig. 1). No proptosis was observed. The rest of the ophthalmologic examination was unremarkable. The patient had no other history of ocular pathology. The initial impression was scleritis, given the erythema of the left eye conjunctiva. Topical steroid was prescribed; the patient was also referred to a rheumatologist for further workup. She returned one month later with no improvement in her symptom. The result of an autoimmune panel was within normal limit (erythrocyte sedimentation rate, ESR $=12 \mathrm{~mm} / \mathrm{h}$, normal: $0-28.5$; IgA $=191 \mathrm{mg} / \mathrm{dl}$, normal: 70-360; antinuclear antibody, ANA = negative, normal: negative; rheumatoid factor, $\mathrm{RF}<20$ $\mathrm{U} / \mathrm{ml}$, normal: $<20 \mathrm{U} / \mathrm{ml}$ ). By the time of her second visit, the color of the mass had turned salmonpink. The patient received an ultrasound B scan to rule out intraocular tumor, but it showed no mass. Since the mass persisted in spite of topical steroid treatment and a negative rheumatological workup, malignant lymphoma was suspected. The differential diagnosis also included amelanotic nevus, dermoid, myxoma, and lipoma. The lesion was subsequently excised and sent for histopathological study.

The specimen consisted of a pinkish tan and soft tissue fragment, measuring $9 \times 6 \times 4 \mathrm{~mm}$. Histopathological examination revealed a benign tumor composed of spindle cells embedded in a myxomatous stroma. No nuclear atypia was seen (fig. 2). The tumor cells stained positive for vimentin ( $\underline{\text { fig. } 3}$ ). The findings were consistent with conjunctival myxoma. The patient returned after one month post-excision for follow-up and no longer complained of pain and redness in her left eye. The patient also received extensive cardiac and endocrine workup. Her echocardiogram showed no mass in the heart. The endocrine workup was only remarkable for a mildly depressed T3 level 0.75 $\mathrm{ng} / \mathrm{ml}$, normal: $0.8-2$ ); TSH, T4, estradiol, and FSH were all within normal limits (T4 = $8.47 \mu \mathrm{g} / \mathrm{dl}$, normal: $5.1-14.1$; $\mathrm{TSH}=1.95 \mu \mathrm{IU} / \mathrm{ml}$, normal: $0.27-4.2$; estradiol $=13.20 \mathrm{pg} / \mathrm{ml}$, normal: $<54.7 \mathrm{pg} / \mathrm{ml}$; $\mathrm{FSH}=100.40 \mathrm{mIU} / \mathrm{ml}$, normal: 25.8-134.8). She had no atypical dermatological findings. 


\section{Discussion}

Conjunctival myxoma is rare, with only 26 cases reported so far in the English literature (table 1). It occurs equally frequently in both sexes; the ages of the patients ranged from 11 to 80 years, with a median of 50 [5-8]. Chen et al. [6] reported the youngest case in an 11-year-old boy; the other cases were in the range of 18-80 years of age. The typical presentation is a translucent, well-circumscribed conjunctival mass, most often at the bulbar conjunctiva. Whereas the masses were painless in the previously reported cases, the patient in this report presented with pain and redness that resembled scleritis; in addition, the margin of the mass was more diffuse than in previously reported cases. It is possible that these symptoms resulted from the medication used by the patient prior to her initial visit, rather than from an actual variation in the presentation of conjunctival myxoma. To our knowledge, only one paper published in Japanese had ocular pain as the initial sign of conjunctival myxoma; no redness was noted in that case, however, unlike in our case [10].

According to a detailed study and literature review by Demirci et al. [5], conjunctival myxoma consists of scattered, relatively small stellate- and spindle-shaped cells embedded in myxoid matrix along with reticulin fibers, sparse vascular structures, and mature collagen fibers. Hyaluronic acid, along with some chondroitin sulfate, constituted the matrix. Conjunctival myxomas stain positive with Alcian blue and vimentin, and negative with S-100 protein, desmin, and smooth muscle-specific actin [8].

It is important to differentiate conjunctival myxoma from other similar lesions, which include nevus, amelanotic melanoma, lymphangioma, myxoid liposarcoma, spindle-cell lipoma, myxoid neurofibroma, and rhabdomyosarcoma. Compared to nevus and lymphangioma, myxoma does not have cysts [9]. In addition, lymphangioma and amelanotic nevus are highly vascular. Liposarcoma is similar to myxoma in being highly mucoid; however, myxoma does not contain pleomorphic multivacuolated lipoblasts or signet ring cells. Spindle-cell lipoma tends to be more yellowish and contains mature fat cells and signet ring cells when compared to myxoma [11].

The recommended management for conjunctival myxoma is complete excisional biopsy [5]. No cases of recurrence or malignant transformation have been reported.

While most reported cases of conjunctival myxoma were isolated occurrences, at least two had systemic involvement and presented as a component of Carney complex or in association with Zollinger-Ellison syndrome [12,13]. Carney complex is an autosomal dominant syndrome first described in the mid-1980s. It can present with multiple endocrine tumors involving the adrenal, pituitary, and thyroid glands, or with Cushing syndrome; it is also associated with many other non-endocrine tumors, such as cardiac myxomas, breast myxomas, testicular tumors, melanotic schwannoma, and abnormal pigmentation. The Carney complex gene 1 had been identified as the regulatory subunit $1 \mathrm{~A}$ of protein kinase A (PRKAR1A) located at 17q22-24 [14]. In addition to Carney complex, myxoma may also be a component of the Mazabraud syndrome (bone fibrous dysplasia and intramuscular myxoma) or of the McCuneAlbright syndrome (café au lait spots and multinodular goiter) [5]. As a result of these associations, systemic evaluation of a patient with conjunctival myxoma, which includes cardiac echocardiography and analysis of hormone levels, is warranted. 
In summary, we present a case of conjunctival myxoma in a 47-year-old Taiwanese woman. The diagnosis was somewhat complicated by the atypical presentation with pain and redness, but the histopathological and immunochemical findings were consistent with those of conjunctival myxoma. The lesion was successfully managed with complete excisional biopsy.

\section{Disclosure Statement}

The authors have no conflicts of interest to declare.

Table 1. The list of reported conjunctival myxoma cases published in English, adapted from Demirci et al. [5], updated with cases reported after the original publication

\begin{tabular}{|c|c|c|c|c|c|c|c|c|c|}
\hline Source & $\begin{array}{l}\text { Age, years/ } \\
\text { sex }\end{array}$ & Systemic disease & Eye & Symptoms & Clinical features & Color & $\begin{array}{l}\text { Conjunctival } \\
\text { site }\end{array}$ & $\begin{array}{l}\text { Conjunctival } \\
\text { location }\end{array}$ & Outcome \\
\hline Ffooks (1962) & $72 / \mathrm{M}$ & None & OD & Conjunctival mass & $\begin{array}{l}\text { Rubbery, circumscribed } \\
\text { subconjunctival mass }\end{array}$ & White & Limbus & Superior & Stable \\
\hline $\begin{array}{l}\text { Doughman and Wenk } \\
\text { (1970) }\end{array}$ & $49 / \mathrm{F}$ & None & OD & Conjunctival mass & $\begin{array}{l}\text { Rubbery, circumscribed } \\
\text { subconjunctival mass }\end{array}$ & Yellow & Limbus & Temporal & Stable \\
\hline Stafford (1971) & $54 / \mathrm{F}$ & None & OD & Conjunctival cyst & $\begin{array}{l}\text { Translucent, circumscribed } \\
\text { subconjunctival mass }\end{array}$ & Pink & Limbus & Temporal & Stable \\
\hline \multirow{4}{*}{$\begin{array}{l}\text { Patrinely and Green } \\
\text { (1983) }\end{array}$} & $50 / \mathrm{F}$ & None & OD & Conjunctival mass & Translucent, diffuse conjunctival mass & Yellow & Bulbar & Nasal & Stable \\
\hline & $\overline{53 / \mathrm{F}}$ & None & OS & Conjunctival cyst & Solid, circumscribed conjunctival mass & Yellow & Bulbar & Temporal & Stable \\
\hline & $\overline{18 / \mathrm{F}}$ & None & OS & Conjunctival mass & $\begin{array}{l}\text { Semitranslucent, circumscribed } \\
\text { conjunctival mass }\end{array}$ & Pink & Bulbar & Superior & Stable \\
\hline & $42 / \mathrm{F}$ & None & OD & Conjunctival mass & $\begin{array}{l}\text { Translucent, circumscribed } \\
\text { subconjunctival mass }\end{array}$ & Yellow & Limbus & Temporal & Stable \\
\hline $\begin{array}{l}\text { Mottow-Lippa et al. } \\
\text { (1983) }\end{array}$ & $54 / \mathrm{M}$ & None & OS & Conjunctival mass & $\begin{array}{l}\text { Translucent, circumscribed } \\
\text { subconjunctival mass }\end{array}$ & Pink & Limbus & Temporal & Stable \\
\hline Pe'er et al. (1984) & $18 / \mathrm{F}$ & None & OD & Conjunctival mass & $\begin{array}{l}\text { Translucent, circumscribed } \\
\text { subconjunctival mass }\end{array}$ & Pink & Bulbar & Nasal & Stable \\
\hline \multirow[t]{10}{*}{ Pe'er and Hidayat (1986) } & $48 / \mathrm{M}$ & None & $\mathrm{NA}$ & Conjunctival cyst & Conjunctival cyst & Yello & Fornix & Inferior & Stable \\
\hline & $\overline{61 / M}$ & None & $\mathrm{NA}$ & $\begin{array}{l}\text { Conjunctival } \\
\text { growth }\end{array}$ & $\begin{array}{l}\text { Solid, circumscribed subconjunctival } \\
\text { mass }\end{array}$ & $\mathrm{NA}$ & Bulbar & Temporal & Stable \\
\hline & $\overline{34 / \mathrm{M}}$ & None & $\mathrm{NA}$ & Conjunctival cyst & Conjunctival cyst & Yellow & Bulbar & Temporal & Stable \\
\hline & $\overline{64 / M}$ & None & $\mathrm{NA}$ & Conjunctival mass & Conjunctival mass & Pink & Bulbar & Temporal & Stable \\
\hline & $\overline{33 / F}$ & None & $\mathrm{NA}$ & Conjunctival mass & Solid, circumscribed conjunctival mass & Pink & Bulbar & $\mathrm{NA}$ & Stable \\
\hline & $20 / \mathrm{M}$ & None & $\mathrm{NA}$ & Conjunctival cyst & $\begin{array}{l}\text { Translucent, circumscribed } \\
\text { conjunctival mass }\end{array}$ & Yellow & Limbus & Temporal & Stable \\
\hline & $\overline{50 / \mathrm{M}}$ & None & $\mathrm{NA}$ & Conjunctival cyst & $\begin{array}{l}\text { Translucent, circumscribed } \\
\text { conjunctival mass }\end{array}$ & Yellow & Bulbar & Nasal & Stable \\
\hline & $\overline{50 / \mathrm{F}}$ & None & $\mathrm{NA}$ & Conjunctival mass & Solid, circumscribed conjunctival mass & Pink & Bulbar & NA & Stable \\
\hline & $\overline{76 / M}$ & None & $\mathrm{NA}$ & Conjunctival cyst & $\begin{array}{l}\text { Translucent, circumscribed } \\
\text { conjunctival mass }\end{array}$ & $\mathrm{NA}$ & Limbus & Superior & Stable \\
\hline & $\overline{65 / F}$ & None & NA & Conjunctival mass & Translucent, diffuse conjunctival mass & $\mathrm{NA}$ & Bulbar & Temporal & Stable \\
\hline Kennedy et al. (1987) & $23 / \mathrm{M}$ & Carney complex & $\mathrm{NA}$ & Conjunctival mass & $\begin{array}{l}\text { Translucent, circumscribed } \\
\text { conjunctival mass }\end{array}$ & Yellow & Palpebral & Superior & Stable \\
\hline Horie et al. (1995) & $80 / \mathrm{F}$ & None & OS & Conjunctival mass & Solid, circumscribed conjunctival mass & $\mathrm{NA}$ & Bulbar & Nasal & Stable \\
\hline Ramaesh et al. (2001) & $36 / \mathrm{M}$ & $\begin{array}{l}\text { Zollinger-Ellison } \\
\text { syndrome and thickness } \\
\text { of atrial septum }\end{array}$ & OD & $\begin{array}{l}\text { Conjunctival } \\
\text { swelling }\end{array}$ & $\begin{array}{l}\text { Translucent, circumscribed } \\
\text { conjunctival mass }\end{array}$ & Pink & Bulbar & Nasal & Stable \\
\hline Demirci et al. (2006) & $31 / \mathrm{M}$ & None & OS & $\begin{array}{l}\text { Conjunctival } \\
\text { swelling }\end{array}$ & $\begin{array}{l}\text { Translucent, circumscribed } \\
\text { conjunctival mass }\end{array}$ & Yellow-pink & Bulbar & Nasal & Stable \\
\hline Chen et al. (2008) & $11 / \mathrm{M}$ & None & OS & Conjunctival mass & $\begin{array}{l}\text { Translucent, circumscribed } \\
\text { conjunctival mass }\end{array}$ & Yellow-pink & Bulbar & Temporal & Stable \\
\hline Arya et al. (2008) & $64 / \mathrm{F}$ & None & OD & $\begin{array}{l}\text { Conjunctival } \\
\text { swelling }\end{array}$ & $\begin{array}{l}\text { Translucent, circumscribed } \\
\text { conjunctival mass }\end{array}$ & Yellow-pink & Bulbar & Superonasal & Stable \\
\hline Kiliç et al. (2008) & $45 / \mathrm{F}$ & None & OS & Conjunctival mass & $\begin{array}{l}\text { Translucent, circumscribed } \\
\text { conjunctival mass }\end{array}$ & Yellow-pink & Bulbar & Temporal & Stable \\
\hline
\end{tabular}




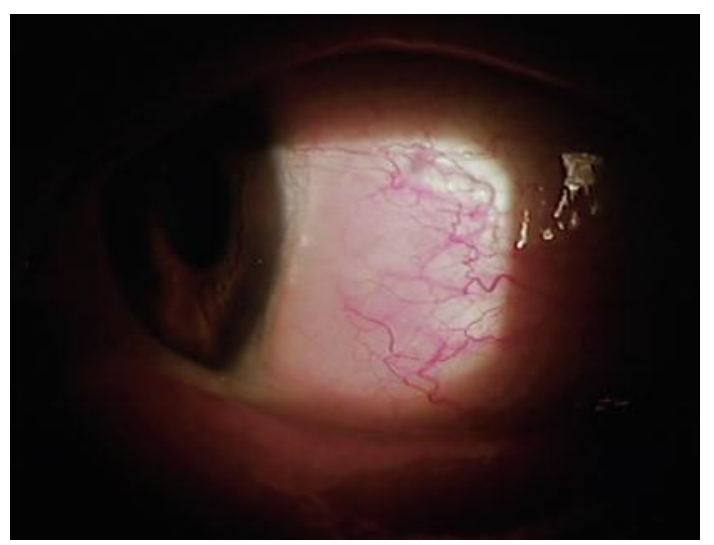

Fig. 1. A circumscribed mass in the temporal bulbar conjunctiva of the left eye, surrounded by region of hyperemia.

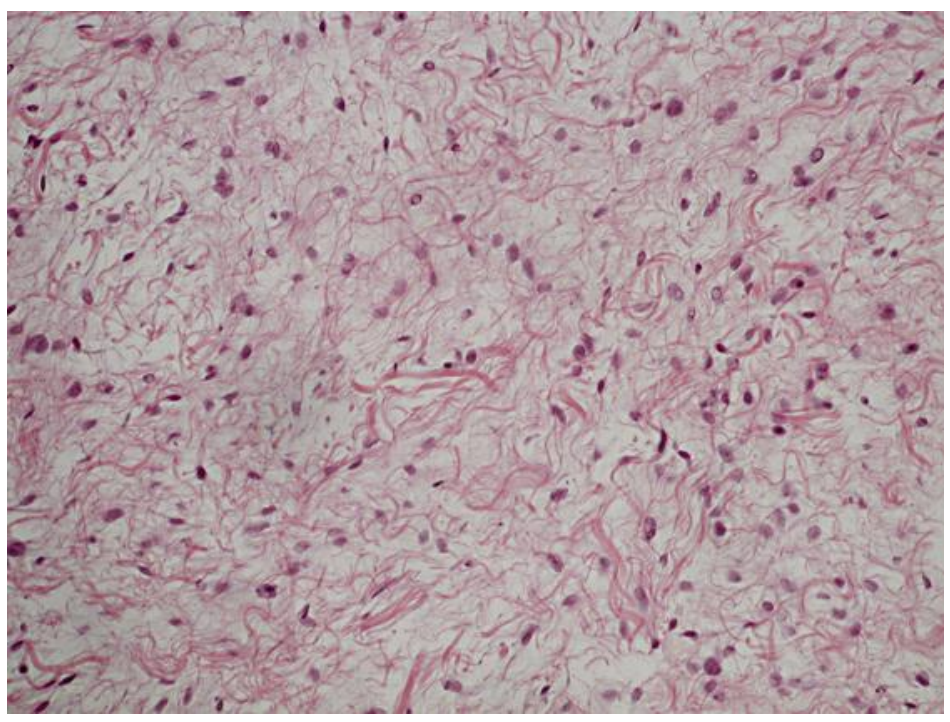

Fig. 2. Scattered spindle cells embedded in a myxomatous stroma (hematoxylin-eosin, original magnification $\times 200$ ). 


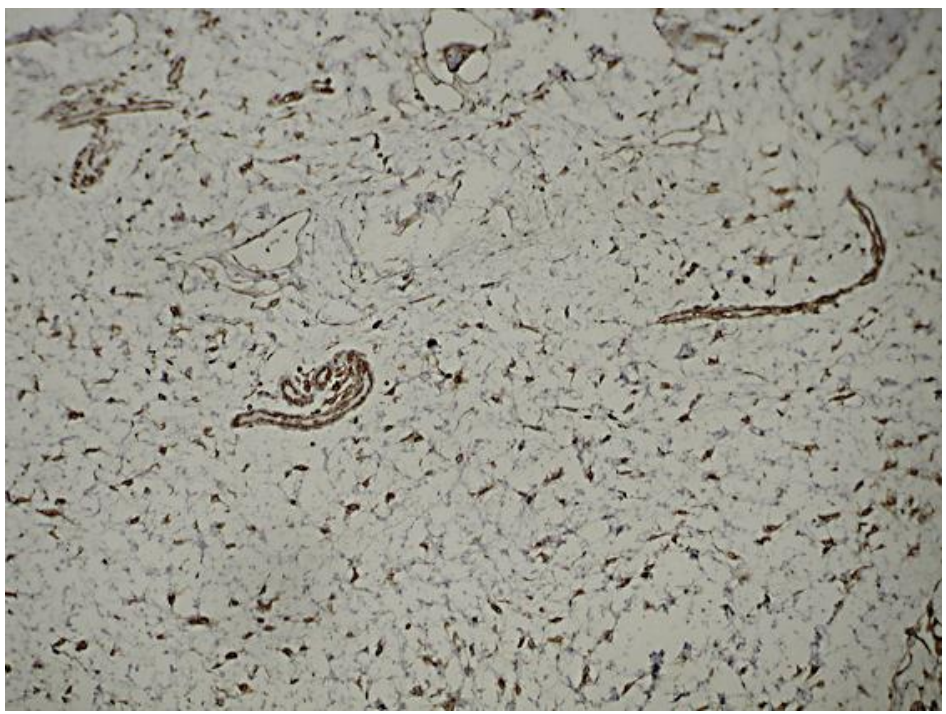

Fig. 3. Tumor cells staining positive for vimentin (immunoperoxidase, original magnification $\times 100$ ).

\section{References}

1 Bulkley BH, Hutchins GM: Atrial myxomas: a fifty year review. Am Heart J 1979;97:639-643.

-2 Lieb WE, Goebel HH, Wallenfang T: Myxoma of the orbit: a clinicopathologic report. Graefes Arch Clin Exp Ophthalmol 1990;228:28-32.

-3 Robinson JW, Brownstein S, Mintsioulis G: Corneal myxoma arising in a patient with repeated phototherapeutic keratectomies. Cornea 2006;25:1111-1114.

-4 Shields CL, Demirci H, Karatza E, Shields JA: Clinical survey of 1,643 melanocytic and nonmelanocytic conjunctival tumors. Ophthalmology 2004;111:1747-1754.

5 Demirci H, Shields CL, Eagle RC, Shields JA: Report of a conjunctival myxoma case and review of the literature. Arch Ophthalmol 2006;124:735-738.

$\checkmark 6$ Chen CL, Tai MC, Chen JT, Chen CH, Jin JS, Lu DW: A rare case of conjunctival myxoma and a review of the literature. Ophthalmologica 2008;222:136-139.

7 Arya SK, Gupta H, Gupta S, Malik A, Samra SG, Sood S: Conjunctival myxoma in a 64-year-old patient. Jpn J Ophthalmol 2008;52:339-341.

8 Kiliç A, Kösem M, Demirok A, Cinal A, Yasar T: Conjunctival myxoma: a clinicopathologic report. Ophthalmic Surg Lasers Imaging 2008;39:514-516.

9 Shields JA, Shields CL: Myxoma, lipoma, and reticulohistiocytoma; in Atlas of Eyelid and Conjunctival Tumors. Philadelphia, PA, Lippincott Williams and Wilkins, 1999, pp 286-287.

10 Konari K, Suzuki J-I, Oyachi H, Ueno T, Nakagawa T: Ocular pain as the initial sign of conjunctival myxoma. Jpn J Clin Ophthalmol 1993;47:1361-1364.

-11 Mottow-Lippa L, Tso MO, Sugar J: Conjunctival myxoma. A clinicopathologic study. Ophthalmology 1983;90:1452-1458.

12 Kennedy RH, Flanagan JC, Eagle RC Jr, Carney JA: The Carney complex with ocular signs suggestive of cardiac myxoma. Am J Ophthalmol 1991;111:699-702.

13 Ramaesh K, Wharton SB, Dhillon B: Conjunctival myxoma, Zollinger-Ellison syndrome and abnormal thickening of the inter-atrial septum: a case report and review of the literature. Eye (Lond) 2001;15:309-312.

14 Vezzosi D, Vignaux 0, Dupin N, Bertherat J: Carney complex: Clinical and genetic 2010 update. Ann Endocrinol (Paris) 2010;71:486-493. 